\title{
Coupling of Wind Power Heating with High Energy-Consuming Industries to Increase Wind Power Consumption in Xinjiang, China
}

\author{
Lubing Xie ${ }^{1}$, Xiaoming Rui ${ }^{1}$, Xiaozhao Fan $^{2}$ \& Ruijing Shi ${ }^{2}$ \\ ${ }^{1}$ School of Energy Power and Mechanical Engineering, North China Electric Power University, Beijing, PR \\ China \\ ${ }^{2}$ College of electrical engineering, Xinjiang University, Urumqi, PR China \\ Correspondence: Lubing Xie, School of Energy Power and Mechanical Engineering, North China Electric Power \\ University, Beijing, PR China. E-mail: xie_lubing@126.com
}

Received: December 1, 2017 Accepted: December 17, 2017 Online Published: December 21, 2017, 2017

doi:10.5539/mas.v12n1p14 URL: https://doi.org/10.5539/mas.v12n1p14

\begin{abstract}
Numerous problems have emerged with the rapid development of wind power in Xinjiang. The predominant problem is the inhibition of the healthy development of the wind power industry by wind power curtailment in Xinjiang. In this study, wind power heating and high energy-consuming industries were coupled to increase wind power consumption in Xinjiang on the load side. The feasibility analysis of wind power heating in Dabancheng showed that the heating load characteristics coincide with the wind characteristics and the electric heating technology can fulfill the requirements for wind power heating. A business model innovation achieved a winwin situation. Furthermore, a wind power heating system was designed in Dabancheng, the boiler capacity and the heat storage capacity were calculated, and a heating system model with heat storage technology was established. Wind power heating with heat storage can improve the consumption of wind power and increase the local electric load and system adjustability. Furthermore, heating with curtailed wind power can save 2942 tons of standard coal as well as reduce 5172 tons of $\mathrm{CO}_{2}, 2.9$ tons of $\mathrm{SO}_{2}, 22$ tons of $\mathrm{NO}_{\mathrm{X}}$, and 2 tons of soot emissions. Non-grid-connected distributed wind power was applied to the high energy-consuming coal chemical industry to reduce wind power curtailment, expand the consumption market, and reduce pollution. A multifunctional wind-photovoltaic complementary system with hydrogen energy storage coupled with traditional high energy-consuming coal chemical industry was established. The implementation plan using wind and solar energy to produce, store, and apply hydrogen energy was proven beneficial. Wind power consumption was improved on the load side. The wind power curtailment problem was reduced by increasing local load using the curtailed wind power to provide clean heat in Dabancheng and constructing the multifunctional windphotovoltaic complementary system. This study will contribute to the healthy and sustainable development of the wind power industry in Xinjiang.
\end{abstract}

Keywords: wind power industry in Xinjiang, wind power heating; wind power curtailment, a multifunctional wind-photovoltaic complementary system, healthy and sustainable development

\section{Introduction}

The problem of wind power curtailment was alleviated in 2014. The proportions of wind power curtailment were reduced in different parts of China, including Xinjiang. The national average utilization time of wind power in China is reduced by approximately $180 \mathrm{~h}$ every year because of the low annual wind speed and other factors. Nevertheless, the problem of wind power curtailment remains a major obstacle to the healthy development of the wind power industry in China. In 2015, the average utilization hours of wind power in China decreased to $1728 \mathrm{~h}$, which is $172 \mathrm{~h}$ less compared with that in 2014. The lowest number of utilization hours (i.e., $1184 \mathrm{~h}$ ) was recorded in Gansu (http://www.nea.gov.cn/2016-02/02/c_135066586.htm).

In 2016 , the new installed capacity was $23.37 \mathrm{GW}$, and the total installed capacity reached $169 \mathrm{GW}$, accounting for more than $7 \%$ of the total installed capacity of electric power in China. Wind power has become the third power sources, only next to thermal power and hydropower. In 2015, wind power curtailment worsened with the growth of the wind power industry in China. The total annual wind power curtailment reached 33.9 billion $\mathrm{kWh}$, which is 21.3 billion kWh higher than or 2.69 times that of 2014. The average wind power curtailment rate was $15 \%$, which is $7 \%$ higher than that in 2014 . The regions with the most severe wind power curtailment were Inner 
Mongolia, Gansu, Xinjiang, and Jilin, whose wind power curtailments were 9.001 billion (18\%), 8.002 billion (39\%), 7.1 billion (32\%), and 2.7 billion kWh (32\%), respectively. The wind power curtailment in 2015 is thus far the most serious in the wind power history of China (http://www.nea.gov.cn/2016-02/02/c_135066586.htm). In 2016, the total wind power curtailment in China reached $49.7 \times 109 \mathrm{kWh}, 4$ times as much as that in 2014 . In Gansu, Xinjiang, Inner Mongolia, Jilin and Heilongjiang five areas, wind power curtailment is close to $80 \times 109$ $\mathrm{kWh}$ in past three years, equivalent to the annual electricity consumption in Tianjin in 2015.

Wind power curtailment can be attributed to various causes, which include subjective and objective as well as internal and external factors (Kane \& Ault, 2015; Luo et al., 2016; Pei et al., 2015). It is caused by a combination of factors. For example, wind power consumption is limited for wind power at the end of the grid when local load is insufficient. The delay in the construction of an outgoing channel prevents wind power from being delivered. Wind power in China is mainly distributed in the "Three-North Region," which comprises the regions with the highest wind power curtailment. One of the major causes of wind power curtailment in the Three-North Region is winter. During winter, power systems exhibit low peak-shaving capacity because thermal power is of utmost importance in the Three-North Region during this season. During seasons with high heating requirements, a thermal power plant adopts the mode of "setting electricity with heat" to meet the needs of users. At night, electric load is in the trough, whereas heating load reaches the peak. Accordingly, the output level of the thermal power plant is high, whereas surplus power space is minimal. However, wind energy is rich, and wind power cannot be connected to the grid. Consequently, a substantial portion of the wind is wasted (Fan et al., 2015; Chalise et al., 2015) (http://zfxxgk.nea.gov.cn/auto87/201303/t20130322_1599.htm?keywords=).

Thus, the problem of wind power curtailment in China is increasing in severity. The State Council and the Energy Bureau issued a series of policies and measures to solve this problem. Important measures to expand wind power consumption and alleviate the problem of wind power curtailment include the following: discarded wind power may be used to produce heat cleanly through a heat storage technology, and non-grid-connected wind power may be consumed by high energy-consuming industries (http://zfxxgk.nea.gov.cn/auto92/201602/t20160216_2202.htm)(http://www.gov.cn/zwgk/2013-09/12/content_24 86773.htm)(http://www.nea.gov.cn/2015-04/17/c_134160176.htm).

This study aims to improve wind power consumption space from the load side by utilizing curtailed wind power to provide clean heat in Dabancheng and constructing a multifunctional wind-photovoltaic complementary system with hydrogen energy storage coupled with the traditional high energy-consuming coal chemical industry in Hami. This system can increase local load to promote wind power consumption and reduce the problem of wind power curtailment.

\section{Study on Wind Power Clean Heating in Salt Lake Street in Dabancheng Wind Farm in Xinjiang}

\subsection{Research Background of Wind Power Heating}

On September 10, 2013, the State Council issued the "Air Pollution Prevention Action Plan" (also referred to as "Atmospheric 10"). Small coal-fired heat and power generating units must be shut down before 2017. Electricity, renewable energy, or clean coal can be switched to heat in some areas.

On March 15, 2013, the National Energy Administration of China, Department of Comprehensive, issued a notice calling for wind power clean heating. During the winter heating period in the northern region of China, wind power clean heating technology can be applied in northern and northwestern China under favorable conditions. This solution can alleviate difficulties in connecting wind power to the grid and operating when the load is in the valley to improve wind power consumption of wind energy-rich regions in the north, to harness clean energy in the city, to mitigate environmental pollution due to the inefficient combustion of fossil fuels, and to solve atmospheric haze and other environmental problems for improved air quality (http://zfxxgk.nea.gov.cn/auto87/201303/t20130322_1599.htm?keywords=)(http://www.gov.cn/zwgk/2013-09/1 2/content_2486773.htm).

From 2013 to 2015, the National Energy Administration released the "National Energy Administration on the Wind Power Grid Connecting Grid and Consumption Relevant Work of the Notice." This notice encouraged the use of wind power clean heating technology to replace traditional heating with coal-fired boilers (http://zfxxgk.nea.gov.cn/auto87/201303/t20130322_1599.htm?keywords=)(http://zfxxgk.nea.gov.cn/auto92/201 602/t20160216_2202.htm)(http://www.gov.cn/zwgk/2013-09/12/content_2486773.htm)(http://www.nea.gov.cn/2 015-04/17/c_134160176.htm).

In the notice, the National Energy Administration clearly requires the use of wind power to produce heat cleanly in accordance with the characteristics of wind energy resources, wind power grid operation, and heating status, 
as well as new city planning construction and local conditions, to improve the local consumption of wind power. Since 2013, the provinces of Inner Mongolia, Jilin, and Hebei have been using wind power for clean heating with good effect. To promote the consumption of wind power, a demonstration project of hydrogen production using wind power was conducted in these provinces. The project provided practical experience in and foundation for the use of wind power.

Wind power clean heating was proposed for the wind farm in Salt Lake Street in Dabancheng, Xinjiang. The production base of Saline Lake Salt Production LLC is located in Dabancheng in Urumqi, Xinjiang. It is $72 \mathrm{~km}$ to the east of Urumqi City and $12 \mathrm{~km}$ to the west of Dabancheng. Tu-Wu Highway, 312 National Highway, and Lan-Xin Railway pass through the base, and transportation is highly convenient. The production base currently has its own thermal power plant, which was built in 1998. The thermal power plant has two YG-35/3.82-M model $35 \mathrm{t} / \mathrm{h}$ circulating fluidized bed boilers and two $3000 \mathrm{~kW}$ steam turbine power generation systems, one for the back-pressure turbine and the other for the condensing turbine. The power plant was restructured in 2013 to function as the heat source for the production and operation of the base. The primary heating medium is steam, and two heat transfer stations are respectively responsible for the production and operation of the heating system. However, in accordance with the national "Atmospheric 10" and related policies in Urumqi, small coal-fired boilers were shut down. Thus, the base has no other heat source apart from clean wind power (http://zfxxgk.nea.gov.cn/auto87/201303/t20130322_1599.htm?keywords=) [9].

In 2014, wind power curtailment in Dabancheng Wind Farm in Xinjiang and its rate reached 680 million kWh and $18.3 \%$, respectively, which significantly exceeded the average level in China. In recent years, the regional wind curtailment rate of Dabancheng Wind Farm was higher than the average level in Xinjiang because of limited delivery capacity and low local consumption. Therefore, wind power consumption channels and market must be actively developed according to local conditions and the characteristics of wind energy resources in Dabancheng.

In March 2015, the Xinjiang Development and Reform Commission constructed a heating system in Dabancheng. This system uses curtailed wind power as the experimental unit of wind power heating in Xinjiang. A tripartite win-win business model that involves the Xinjiang power grid, wind power enterprises, and heating companies was established, and the pricing and scheduling system for wind power clean heating was optimized. These measures can promote the healthy development of wind power in Xinjiang.

\subsection{Dabancheng Wind Farm Planning and Wind Power Curtailment}

\subsubsection{Dabancheng Wind Farm Planning}

Urumqi is located in the north-central part of Xinjiang, which is the capital of the autonomous region as well as the political, economic, and cultural center of Xinjiang. It is an important gateway to the opening up of China and the bridgehead of the new Eurasian Continental Bridge in Western China. Urumqi is located in the geographic center of the Asian continent. It is an important city in Central Eurasia and the core of the Silk Road Economic Belt (Biviano et al., 2015; Chen et al., 2016; Li et al., 2015).

The annual average wind speed in Dabancheng Wind Farm is $7.18-10.31 \mathrm{~m} / \mathrm{s}$, and wind power density is $431.2-$ $1197.5 \mathrm{~W} / \mathrm{m} 2$. Before the end of 2014, the planned wind power installed capacity of $4050 \mathrm{MW}$ was approved, and the grid connected wind farm capacity reached $1470 \mathrm{MW}$. Before March 2015, the capacity of the approved and built aerogenerators in Dabancheng Wind Farm reached 2237.65 MW. In 2015, Dabancheng Wind Farm installed aerogenerators, each with a capacity of $1141.5 \mathrm{MW}$ and a cumulative capacity of $2237.65 \mathrm{MW}$, which is double the installed capacity in 2014 (Shi et al., 2017; Wang et al., 2016).

The revised "2012 Report on Wind Farm Project Planning in the Xinjiang Uygur Autonomous Region Dabancheng" presents the planned installed capacity of Dabancheng Wind Farm in Xinjiang by the end of the "Twelfth Five-Year Plan" (Figure 1) (Ma et al., 2013; Xue et al., 2015; Yang \& Chen, 2016). The planned installed capacity of the aerogenerators in Dabancheng Wind Farm by the end of 2015 was 3950 MW. In the "Thirteenth Five-Year Plan," the capacity of the newly installed aerogenerators is expected to increase to approximately 3000 MW. By the end of 2020, the total installed capacity of Dabancheng Wind Farm will reach $6950 \mathrm{MW}$. 


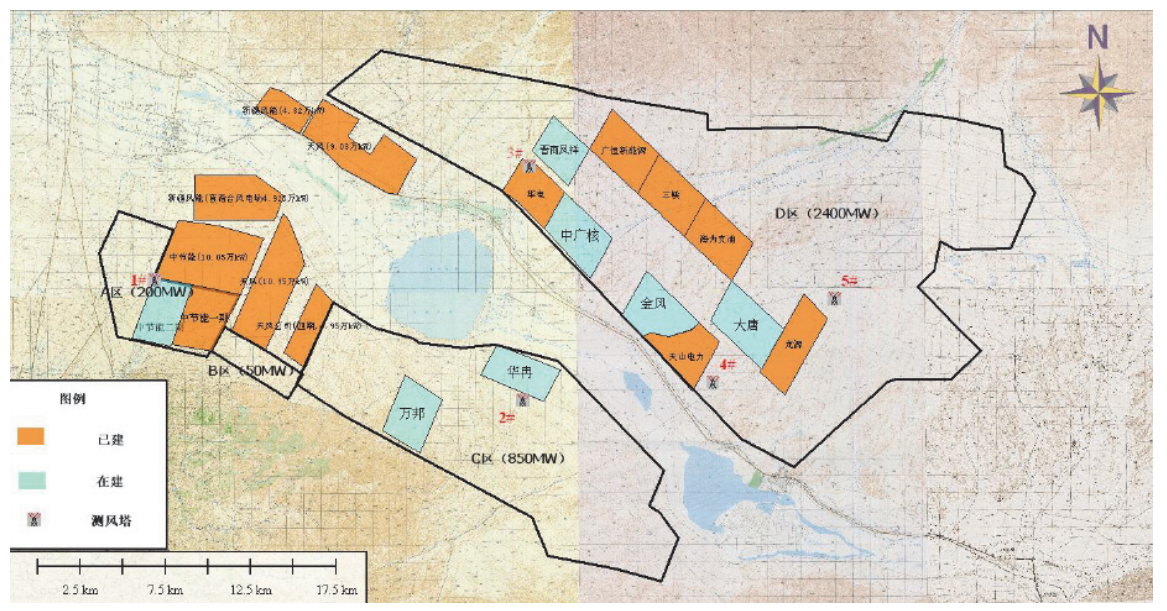

Figure 1. Diagram that the wind farm planning installed capacity in Xinjiang Dabancheng wind area by the end of " the twelfth five-year"

Dabancheng is divided into A, B, C, and D districts. The total capacity of the installed aerogenerators is 3500 MW, and their wind power utilization hours reach 2300-2900 $\mathrm{h}$.

\subsubsection{Wind Power Curtailment in Dabancheng}

According to the current situation and planning of wind power development in Dabancheng wind area, in 2015, the installed aerogenerator capacity of wind area in Dabancheng was $1141.5 \mathrm{MW}$, which was $104.15 \%$ higher than that in the year of 2014. The installed aerogenerator capacity of Dabancheng wind power by the end of 2015 was $2237.65 \mathrm{MW}, 6950 \mathrm{MW}$ in 2020 , Dabancheng wind power would maintain rapid growth momentum. However, similar to most wind farms in China, Dabancheng Wind Farm encounters "re-development, light use" problems. The sharp increase in wind power capacity results in the annual increase in the power curtailment rate (http://www.cec.org.cn/yaowenkuaidi/2013-01-18/96345.html).

Wind power curtailment is calculated based on the transmission (in 2012) No. 154 notice of the State Electricity Regulatory Commission General Office Document Office released that named "on the issuance of calculation method of wind power curtailment of wind power plant (Trial)," where the sample machine method is used.

Limited power $=\Sigma$ (theoretical power generated during limited power period - actual power generated during limited power period)

Theory of power generation $($ time $=$ fan model generation machine/fan model capacity) $\times$ wind power capacity.

Theoretical power generated during limited power period = (power generation of wind-driven generator pattern/ power of wind-driven generator pattern) $\times$ operating power of wind power plant.

In March 2015, the National Energy Administration issued a notice on the grid connection and consumption of wind power. The notice also pointed out that the scale of wind power would expand and the problem of wind power curtailment would intensify in the Three-North Region in 2015. In the present study, an evaluation index for grid-connected wind power operation is proposed, and a power operation model and scheduling system suitable for large-scale wind power networks are established by considering the wind energy resources and operation status of the power grid. The clean heating scale using curtailed wind power is related to the level and characteristics of local wind power curtailment (http://www.cec.org.cn/yaowenkuaidi/2013-01-18/96345.html).

Wind power curtailment rationing in several wind power provinces in China has become serious in recent years. Xinjiang is no exception. The wind power curtailment situations in Xinjiang and Dabancheng in 2012-2015 are shown in Table 1 (Fan et al., 2015; Shi et al., 2017).

Table 1. Situation of wind power curtailment in Xinjiang and Dabancheng district from 2012 to 2015 (Wind power curtailment:WRC $108 \mathrm{kWh}$, Wind power curtailment rate:WRCR \% )

\begin{tabular}{lllllllll}
\hline \multirow{2}{*}{ District } & 2012 & & 2013 & & 2014 & \multicolumn{2}{c}{2015} & \\
& WRC & WRCR & WRC & WRCR & WRC & WRCR & WRC & WRCR \\
\hline Dabancheng & 0.83 & 5.57 & 2.4 & 9.2 & 6.8 & 18.3 & 71.1 & 32.45 \\
Xinjiang & 1.98 & 3.8 & 6.8 & 8 & 23.3 & 15 & 14.86 & 28.27 \\
\hline
\end{tabular}


The wind power curtailment rate was not extremely high in 2012 and remained within the acceptable range. In 2013, the total curtailed wind power volume was 240 million kWh in Dabancheng Wind Farm, the wind power curtailment rate was $9.2 \%$, and the average utilization hours totaled $2608 \mathrm{~h}$. In 2014 , the installed capacity was $1096 \mathrm{MW}$; the total curtailed wind power volume was 680 million $\mathrm{kWh}$; the wind power curtailment rate was $18.3 \%$, which was considerably higher than the national average; and the average utilization hours were $2540 \mathrm{~h}$. Wind power curtailment in Dabancheng in 2015 is the most serious by far. In 2012, 2013, 2014, and 2015, the curtailed wind power in Dabancheng accounted for $41.92 \%, 35.29 \%, 29.18 \%$, and $20.9 \%$, respectively, of Xinjiang. Total power curtailment was extremely high during these years, and thus, extremely serious. The overall trend of the wind power curtailment rate increased from $5.57 \%$ to $9.2 \%$ to $18.3 \%$ to $28.27 \%$, and the volume of curtailed wind power doubled (Fan et al., 2015; Shi et al., 2017).

Therefore, wind power curtailment should be solved using appropriate measures, such as the establishment of a wind power grid, heating, wind power storage, and wind power hydrogen production, to expand the wind power market.

By the end of September 2015, the installed capacity of the Xinjiang grid reached 56.054 million $\mathrm{kW}$ and that of Dabancheng reached 2 million $\mathrm{kW}$ (including new 400,000 kW). In consideration of the power grid structure constraints, the capacity of the three $220 \mathrm{kV}$ main transformers in Salt Lake was 540,000 kW. In accordance with the requirements for stability of the main transformer, the transmission capacity should not exceed $450,000 \mathrm{~kW}$, but the actual transmission capacity was $700,000 \mathrm{~kW}$. The theoretical wind power curtailment rate was $43 \%$. A wind power plant in Salt Lake Wind Farm had access to the No. 2 main transformer. For the stability of the main transformer, the accessed capacity should be $150,000 \mathrm{~kW}$; however, the actual accessed capacity was 300,000 $\mathrm{kW}$. The theoretical power curtailment rate was $30 \%$ (Fan et al., 2017).

In the first four months of 2014, the load could reach 10,000 kWh. The load became limited in May. The accumulated limited load was $13,898,100 \mathrm{kWh}$, and the power curtailment rate was $16.04 \%$. In 2015 , the wind turbine operation became stable, and the power generation capacity was enhanced. However, wind power curtailment gradually became serious. The most serious wind power curtailment occurred in September and reached a rate of 60.63 because the Longmen frame of the main transformer of the Dabancheng $750 \mathrm{kV}$ substation broke down on September 13, thereby dividing the $220 \mathrm{kV}$ and $750 \mathrm{kV}$ networks.

The limited load situation of the wind power plant in 2014 and 2015 is illustrated in Figure 2. In 2015, the limited load was consistently higher than that in 2014, except in November 2015. The total limited load in 2015 was approximately 10 times that in 2014.

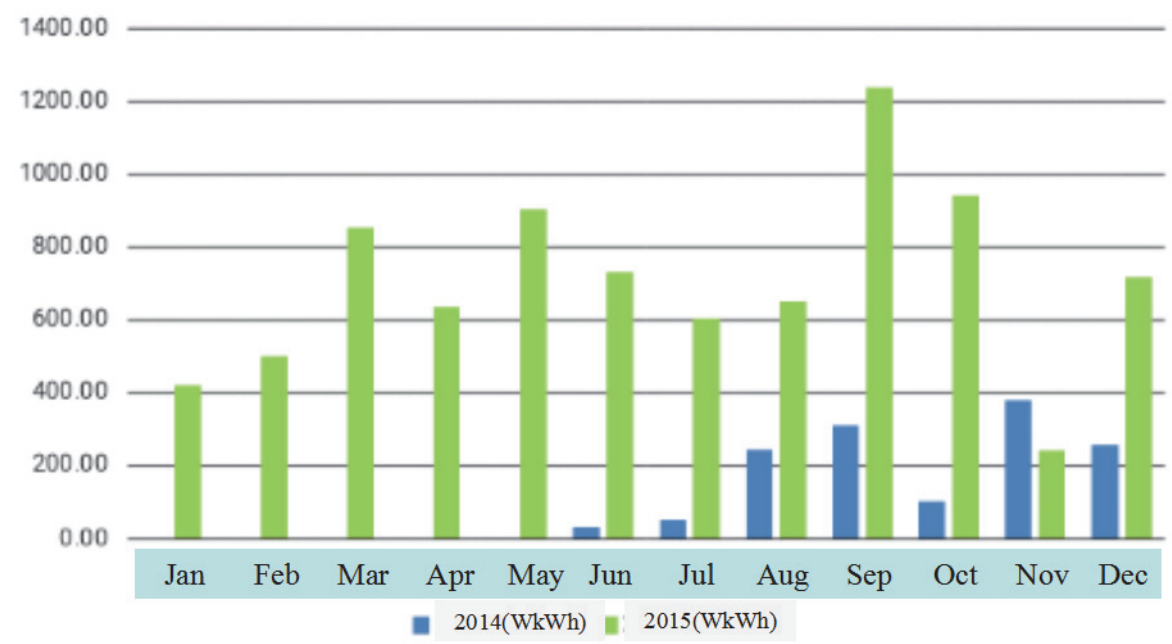

Figure 2. The limited load situation of a wind power plant of Dabancheng wind area in 2014-2015

A comparison of the wind power curtailment rates between 2014 and 2015 is provided in Figure 3. Similarly, the November 2015 wind power curtailment rate was lower than that in 2014, whereas the wind power curtailment rates in the remaining 11 months of 2015 were significantly higher than those in 2014. The wind power curtailment rates in 2014 and 2015 were 15\% and 40\%, respectively. Thus, wind power curtailment in 2015 was extremely serious, and solutions that can expand the channels of wind power consumption are imperative. 


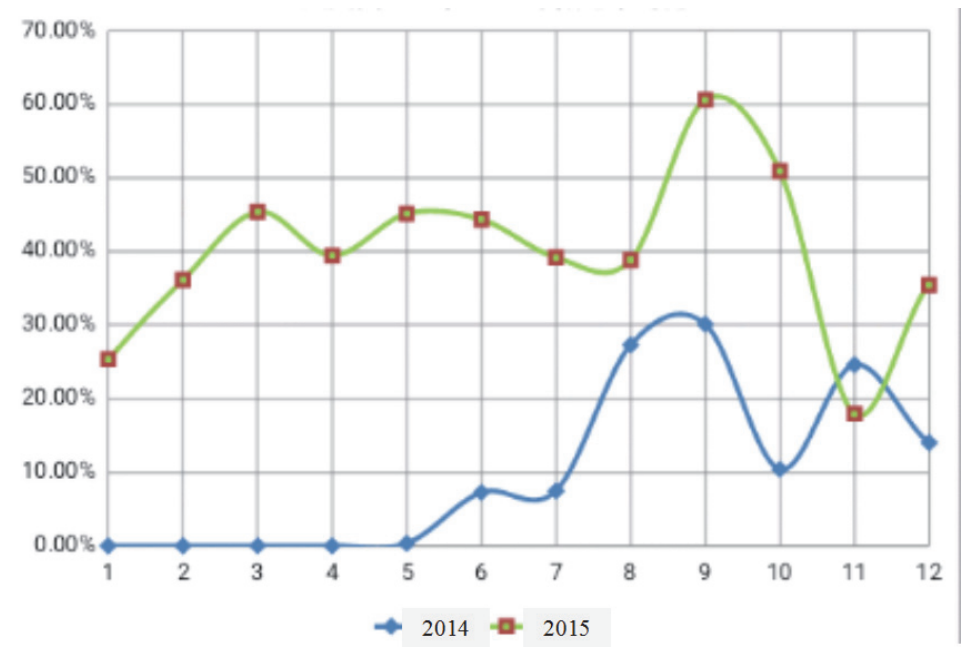

Figure 3. The wind power curtailment situation of a wind power plant of Dabancheng in 2014-2015

\subsection{Feasibility Analysis of Wind Power Heating in Dabancheng}

\subsubsection{Analysis of Heating Load Characteristics and Wind Energy Characteristics}

From the beginning of October 2014, the heating load in Urumqi gradually increased until it reached the maximum load around January 2015. Thereafter, it gradually decreased until the end of heating in April 2015. The 2014-2015 heating load variation of a heating company in Urumqi is shown in Fig. 4. The load gradually increased with a decrease in temperature during winter. The load reached the highest point in December and January. Then, the heating load decreased gradually with an increase in temperature.

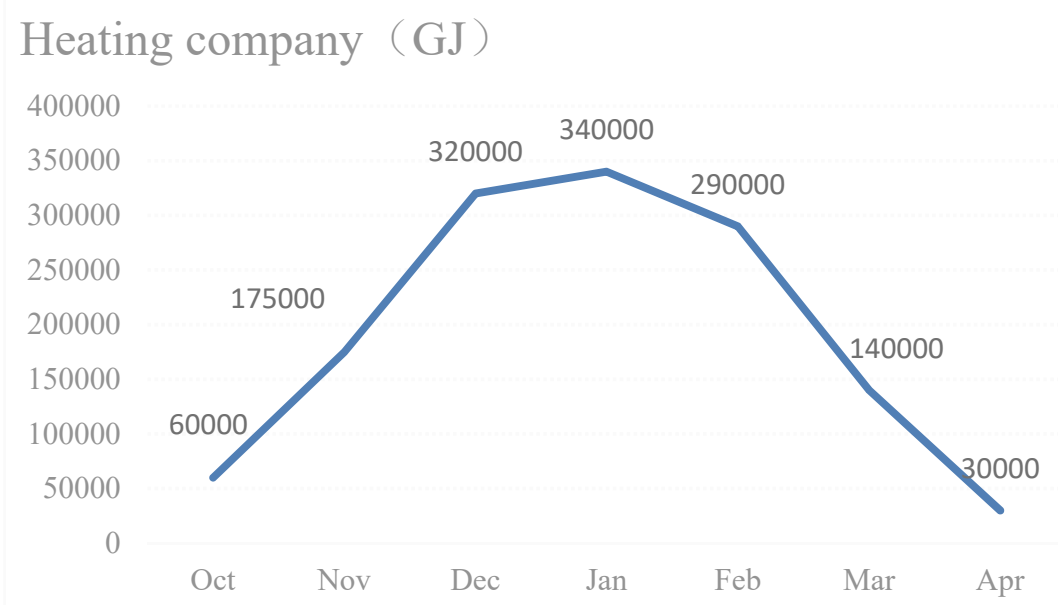

Figure 4. The load heating change situation of a heating company in Urumqi 2014-2015

The average monthly wind speed in the Dabancheng weather station in 1980-2014 is shown in Fig. 5. The average wind speed was $5.8 \mathrm{~m} / \mathrm{s}$. The main wind direction was west-northwest.

The average wind speed gradually increased from the beginning of October 2014 and reached its highest value in December, after which it began to decline. From the beginning of February 2015, wind speed began to increase. It maintained its peak value from April to May. Subsequently, it began to decline until it reached its lowest value from July to September. Wind speed was relatively high in winter and spring. It was close to $7 \mathrm{~m} / \mathrm{s}$ in December, April, and May. Wind speed was lower in summer and autumn, falling below $6 \mathrm{~m} / \mathrm{s}$ in August, September, and October.

As shown in Fig. 5, the heating period in Urumqi from October 2014 to April 2015 was consistent with the time of high wind speed in Dabancheng. 
Average wind speed $(\mathrm{m} / \mathrm{s})$

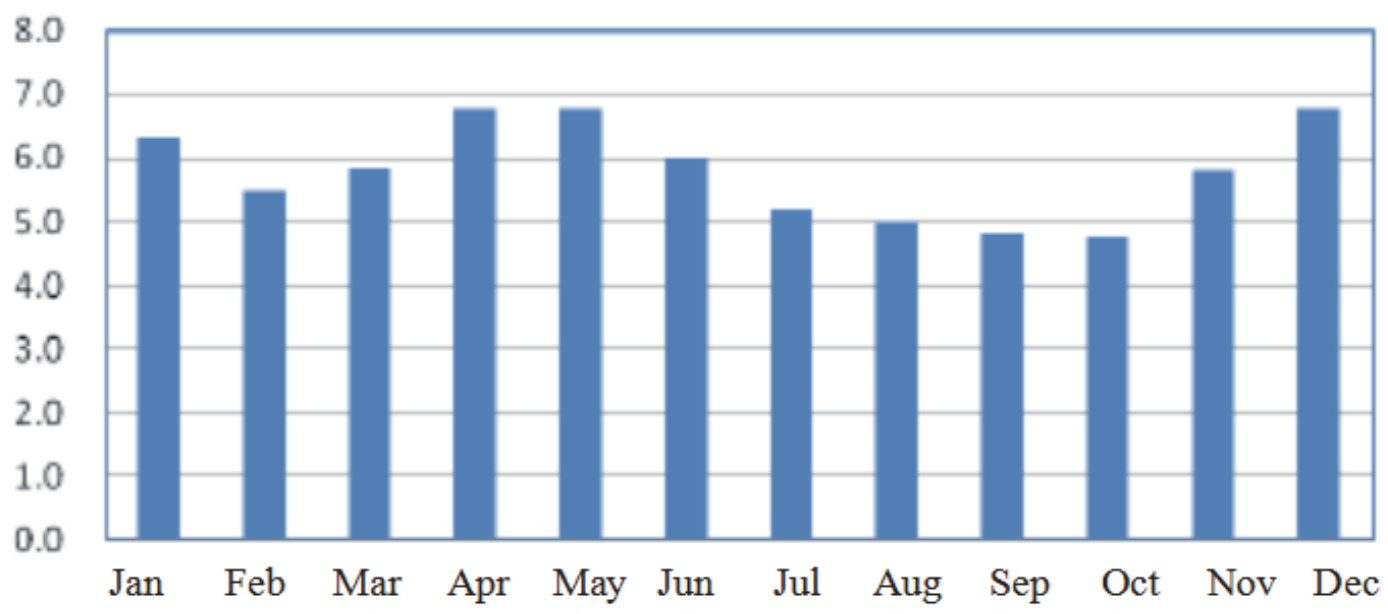

Figure 5. Average wind speed in Dabancheng wind area in 1980-2014

The diurnal variation curve of the monthly mean wind power density in Dabancheng from October 2014 to April 2015 is shown in Fig. 6.
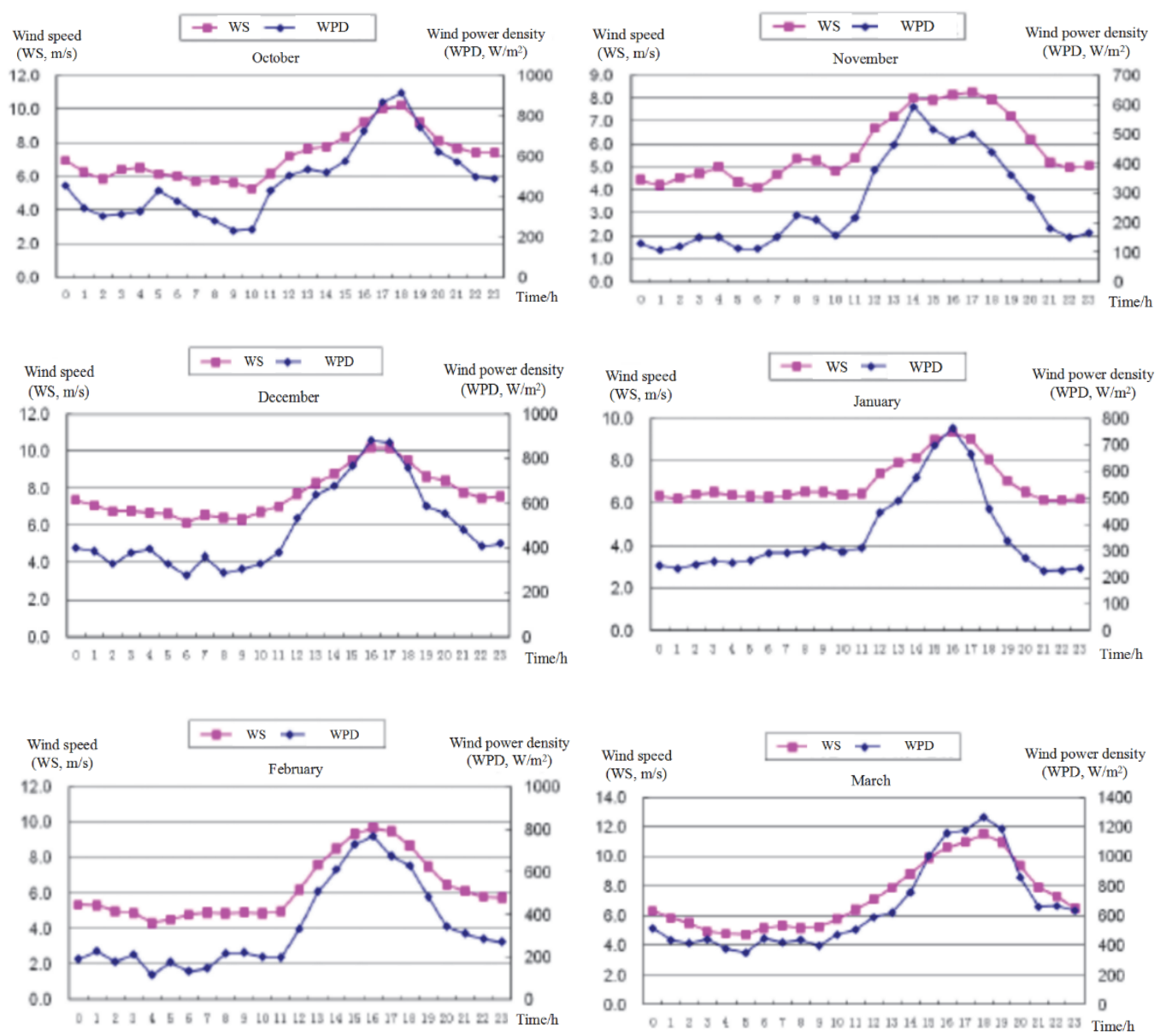

Figure 6. Diurnal variation curve of monthly average wind power density in Dabancheng wind area (2014.10-2015.3)

As shown in Fig. 6, the maximum wind speed generally appeared at around 19:00 and began to decline at 0:00. A 
smooth transition period followed. Then, wind speed began to increase at 8:00 until it reached its maximum value. Although it fluctuated, the overall wind speed process remained unchanged. The wind power density fluctuation range was larger, and the maximum wind power density appeared between 16:00 and 18:00.

The peak-normal-valley power time division of the Urumqi power grid is as follows: valley at 0:00-8:00 and15:00-17:00; peak at 11:00-13:00 and 19:00-21:00; and normal at 8:00-11:00, 13:00-15:00, 17:00-19:00, and 21:00-24:00.

In summary, the wind power clean heating project with heat storage is consistent with the wind energy in a day because heating load is mainly concentrated in the power grid valley.

\subsubsection{Electric Heating Technology Fulfills Wind Power Requirements}

The wind power heating system comprises the electric boiler and the heat storage system. During low load at night, wind power heats the medium by using an electric boiler. The medium is typically water because of its low cost, high calorific value, and stability. Heat can be stored in the heat storage system during daytime and released to the user during the daytime grid peak period.

The conversion of high-quality electric energy into low-quality heat energy for heating is undesirable from the thermodynamic point of view because energy utilization is uneconomical. By contrast, using curtailed wind power for heating is cost-effective. The foremost advantage of heating using curtailed wind power is that it is environmentally safe because it does not aggravate pollution. At present, the state grid and heating company can gain profit given the state subsidies and the price difference between wind and thermal power electricity. Therefore, electric heating is acceptable due to the low cost of wind power heating.

Electric boilers are divided into two types: resistance and electrode. Resistance-type electric boilers have low technical requirements and mature technology. Furthermore, their applications are more extensive than those of electrode-type electric boilers. However, their stand-alone capacity is low because of the layout structure of their electric heating elements and low heating density. Their highest capacity is $2800 \mathrm{~kW}$. For electrode-type electric boilers, water is used as the heating element. Electric energy is converted into the heat energy of water. The stand-alone capacity of electrode-type electric boilers is high and can reach $40 \mathrm{MW}$. However, the technology of these boilers is high, and their applications in China are relatively limited. Both types of boilers are applied in the demonstration project of wind power clean heating in China.

Heat storage media include water, solid materials, and phase change materials. Water is widely used for urban heating in China because it is safe, reliable, and stable. Furthermore, the heat storage technology for this medium is mature and the heat storage equipment is simple and low cost. Solid electric energy storage boilers are also used. The functional principle of this type of boilers is the dominant use of high-voltage synthetic materials of magnesium oxide to produce heat with electricity. Heat is stored in solid materials and connected to a high-temperature heat exchanger through heat output controllers. Heat is supplied by heating water on demand.

In summary, the technology is mature regardless of whether it uses an electric boiler or a thermal storage system, thereby laying the technical foundation for wind power heating.

\subsubsection{Business Operation Model}

A multi-win-win situation is achieved through a business model innovation. The implementation of clean heating projects is supported, and the healthy development of the wind power industry is promoted in Xinjiang. The government proposes a new operation model, which sets a heat station as an independent accounting subject. A heating enterprise invests on, constructs, and operates a heat station. Simultaneously, wind power enterprises provide subsidies to a heating station because of additional power generation.

The promotion of wind power clean heating in Dabancheng Wind Farm improves the local consumption of wind power to promote the development and utilization of wind energy, as well as increases the local gross national product and tax revenue to provide increased revenue and employment. Moreover, the wind power clean heating project can reduce emissions of dust from coal-fired heating, $\mathrm{SO}_{2}, \mathrm{NO}_{\mathrm{x}}$, and other pollutants. Thus, this project can improve the quality of the air and the environment.

\subsection{Dabancheng Wind Power Heating System}

The Salt Lake Street wind power curtailment heating project of the State Power Investment Corporation is located in Salt Lake Street in the Dabancheng District of Urumqi, Xinjiang. The curtailed wind power is used for heating. The total investment is over 2200 yuan, and the project is divided into three phases. The heating system is shown in Fig. 7. The curtailed wind power is random and volatile due to the influences of power grid scheduling and weather conditions. The maximum, minimum, and normal power times of the price difference is 
considered. The wind power clean heating project uses a water storage system because of the advantages of water, as mentioned in Section 2.3.3. In accordance with its size, a heating station uses curtailed wind power and valley power to store heat but uses normal power to provide heat directly. Electricity consumption is the priority of curtailment, and valley power and normal power are not used. Boiler power and heat storage power can be calculated via the valley and normal operation plan (Wu et al., 2016; Liu et al., 2016; Alahäivälä et al., 2017).

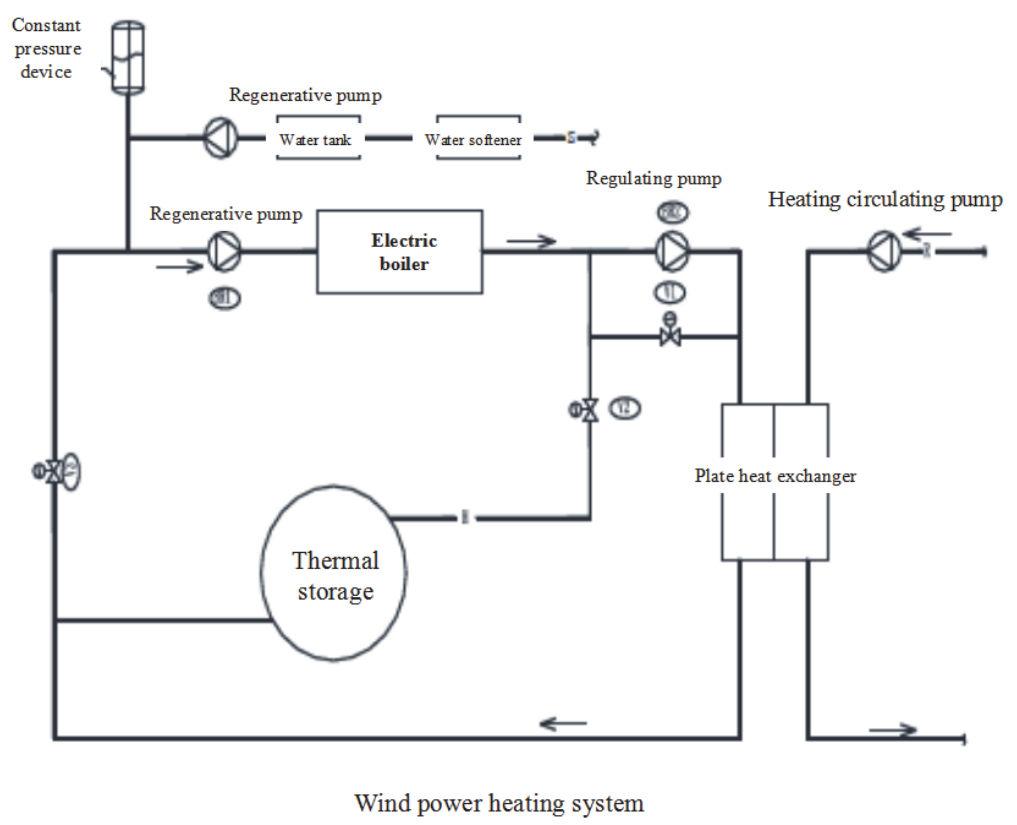

Figure 7. Wind power heating system in Dabancheng

The descriptions of the heat source, heating network, and heating load are presented as follows.

(1) Heat source

The heat storage system of a heating station has four $2200 \mathrm{~kW}$ resistance-type electric boilers. The total power capacity of the system is $8800 \mathrm{~kW}$. This system also has three $185 \mathrm{~m} 2$ heat storage tanks and covers an area of $1122 \mathrm{~m} 2$.

(2) Heating network

The heating area is Salt Lake Street in Dabancheng District. The existing infrastructure includes a single-deck heat exchange station and a bathroom. The existing heating network of Salt Lake Street was reformed in 2014.Its heating performance is perfect. The new heating station is located in the original heat exchange station site. The network does not require large-scale transformation because the new heating station is located at the starting point of the heat source.

(3) Heating load

In the winter of 2015, the heating area of the wind power clean heating project in the Dabancheng Salt Lake base was $100,000 \mathrm{~m} 2$. The annual curtailed wind power of the wind power plant was $15,663,300 \mathrm{kWh}$. In addition, the construction in 2016 was divided into two phases, and the scale of the two phases was $60,000 \mathrm{~m} 2$. It includes the planning of the living area and production area of the office buildings. The third phase is combined with natural gas or other forms of energy to provide steam for operation and production.

The time length of valley power in Xinjiang is $10 \mathrm{~h}$, and occurs at 0:00-8:00 and15:00-17:00. The normal period is $10 \mathrm{~h}$ and occurs at 8:00-11:00, 13:00-15:00, 17:00-19:00, and 21:00-24: 00. The peak period is $4 \mathrm{~h}$. Boiler power and heat storage power can be calculated using the valley and the normal operation plan (Wu et al., 2016; Liu et al., 2016; Alahäivälä et al., 2017).

(1) Heating load of duty boiler 


$$
H_{g}=Q \cdot n_{1} / n_{2}
$$

where $\mathrm{Ng}$ is the boiler capacity, $\mathrm{kW}$; $\mathrm{Q}$ is the planned heating load, $\mathrm{kW} ; \mathrm{n} 1$ is the unbalanced period correction factor; and $\mathrm{n} 2$ is the electric boiler thermal efficiency.

(2) Heat storage boiler heating load

$$
N_{x}=\frac{Q \cdot T_{f} \cdot \eta}{T \cdot n_{2}}
$$

where $\mathrm{Nx}$ is the heating load of the heat storage boiler, $\mathrm{kW}$; $\mathrm{Tf}$ is the peak power time length, $\mathrm{h} ; \mathrm{T}$ is the heat storage time (local valley power time length), $h$; and $\eta$ is the heat loss rate.

(3) Calculated boiler heating load

$$
N=N_{g}+N_{x}
$$

where $\mathrm{N}$ is the calculated heating load of the boiler, $\mathrm{kW}$.

(4) Effective volume of thermal storage device

$$
V=\frac{\left(N-N_{g}\right) \cdot T \cdot 3600}{\Delta t \cdot \eta_{1} \cdot \eta_{2} \cdot \rho \cdot 4.18}
$$

where $\mathrm{V}$ is the effective volume of the thermal storage device, $\mathrm{m} 3 ; \eta 1$ is the heat storage tank insulation rate; $\eta 2$ is the storage tank volume rate; $\Delta \mathrm{t}$ is the available temperature difference, ${ }^{\circ} \mathrm{C}$; and $\rho$ is the hot water density.

The calculated boiler capacity and heat storage capacity are shown in Table 2.

Table 2. Calculation results of boiler capacity and heat storage capacity

\begin{tabular}{cccc}
\hline Heating area $/ \mathrm{m}^{2}$ & Heating load $/ \mathrm{kW}$ & Boiler capacity $/ \mathrm{kW}$ & High temperature storage tank volume $/ \mathrm{m}^{3}$ \\
\hline 100000 & 6000 & 8700 & 550 \\
\hline
\end{tabular}

\section{(5) Heat exchanger area}

A plate heat exchanger is generally used as the heat exchanger of the heating boiler. The heat exchanger area is calculated using

$$
F=\frac{Q}{\Delta t_{c p} \cdot K}
$$

where $\mathrm{F}$ is the heat exchanger area, $\mathrm{m} 2$; $\mathrm{Q}$ is the heating load, $\mathrm{W} ; \Delta \mathrm{tcp}$ is the logarithmic average temperature difference, ${ }^{\circ} \mathrm{C}$; and $\mathrm{K}$ is the plate for the heat transfer coefficient, $\mathrm{W} /\left({ }^{\circ} \mathrm{C} \mathrm{m} 2\right)$. The logarithmic average temperature difference can be derived by

$$
\Delta t_{c p}=\frac{\Delta t_{d}-\Delta t_{x}}{\ln \left(\Delta t_{d} / \Delta t_{x}\right)}
$$

where $\Delta \mathrm{td}$ is the temperature difference of the maximum temperature difference points, ${ }^{\circ} \mathrm{C}$; and $\Delta \mathrm{tx}$ is the temperature difference of the minimum temperature difference points, ${ }^{\circ} \mathrm{C}$.

After the calculation, the required plate heat exchanger area of the Dabancheng heating station is determined to 
be $250 \mathrm{~m} 2$, which includes $10 \mathrm{~m} 2$ for the radiant floor heating system and $240 \mathrm{~m} 2$ for the radiator heating system.

The operation model for heat storage affects the electric boiler and the heat storage capacity. The total investment and operation cost are also affected. The operation model for heat storage should not only reduce the investment of the project but also its operation cost. The model should also reflect the role of heat storage on wind load given that the core technology of the heating system is heat storage. The subsequent section presents the modeling of the heating system with heat storage technology.

\subsection{Modeling of the Heating System with Heat Storage Technology}

\subsubsection{Energy Storage for Heating Systems}

High-power-capacity energy storage technology is also one of the main solutions to the power shortage problem. At present, pumped storage is the most mature energy storage technology. Other energy storage systems should be improved in the areas of capacity scale, technical level, equipment manufacturing, and cost. Energy storage is currently used in thermal-electrical systems in China. The working principle of this technology is shown in Fig. 8. Energy storage technology is used on the power side to improve thermal power plant capacity. It is also used on the load side to expand wind power heating regulation space and promote the local consumption of wind power (Yuan et al., 2013).

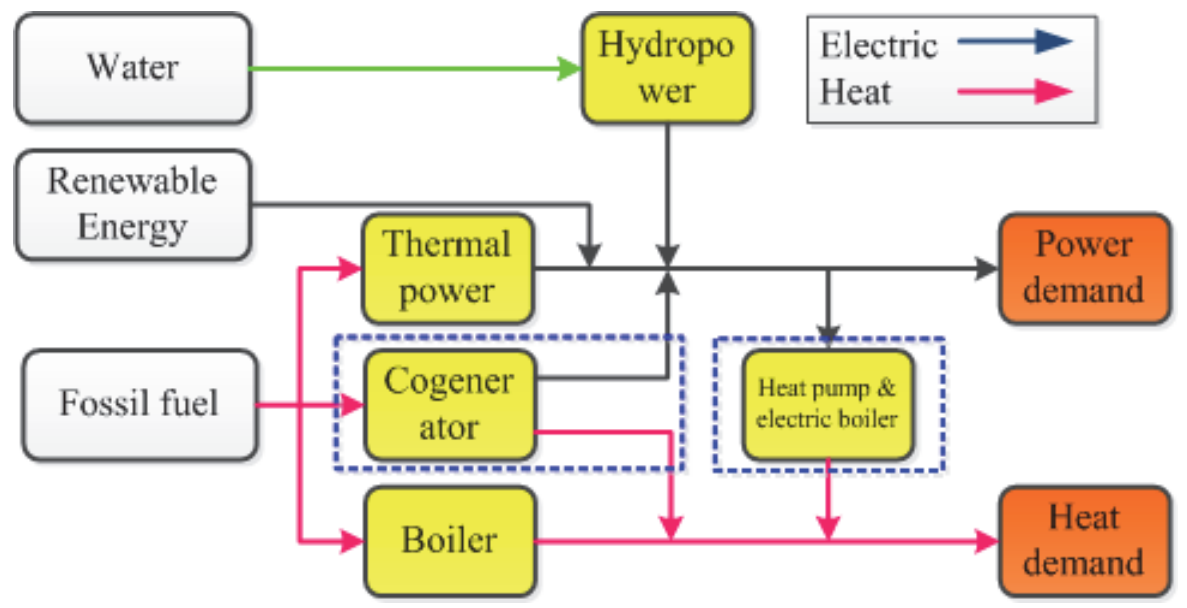

Figure 8. Energy storage for thermal-electrical system

In the literature (Li et al., 2012; Long et al., 2013; Quan et al., 2014; Fei et al., 2014), heat pumps, electric boilers, and other electric heating technologies were used to minimize the connected grid contradiction between wind power and thermal power plants and improve the regulation of space. A previous study (Quan et al., 2014) reviewed the application prospects of high-capacity heat storage electric heating systems. Electric and thermal systems have differences and similarities. The key technologies of an energy integrated system were analyzed using a mathematical model and a control strategy. An integrated scheduling model for an electric power system with heat storage was established in a previous study (Lei et al., 2015). In the current study, a wind power heating scheduling and optimization control model that includes heat storage is constructed, and the effects of heat storage and wind power booster are simulated and analyzed.

\subsubsection{Wind Heating System with Heat Storage}

Since 2013, the National Energy Administration has issued a series of wind power consumption policies, which include wind power clean heating. The use of curtailed wind power for heating can increase the local load and local consumption capacity of wind power. Without heat storage, wind power clean heating applies the principle of "heat decides electricity." That is, the electric load is determined by the heating load. Thus, the adjustment space is small, and the degree of thermal-electrical coupling decreases. Consequently, maximizing curtailed wind power is difficult. If the heat storage system is added, then electric heating load adjustment will be highly flexible, as shown in Fig. 9. Furthermore, wind power can be maximally utilized depending on the situation of wind power curtailment. 


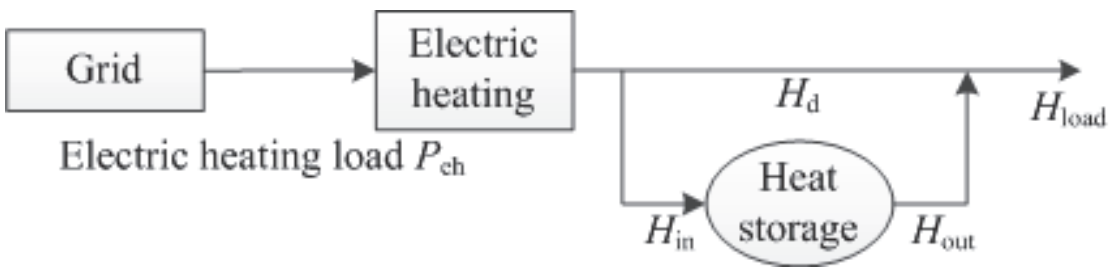

Figure 9. wind power heating system of heat storage

\subsubsection{Model for the Combined Thermal-Electric System with Heat Storage}

The physical and mathematical models for the thermal-electric system with heat storage should be established given that this system differs from traditional power systems. In accordance with the law of conservation of energy, the models for the heat storage device and the electric heating system are established as follows (Quan et al., 2014; Lei et al., 2015).

\section{Heat storage device}

(1) Heat storage capacity

In the heat storage system, the heat storage capacity $\mathrm{Ss}$ is lower than the maximum heat storage capacity $S_{\max }$ (i.e., $0 \leq S_{s} \leq S_{\max }$ ).

(2) Heat storage power

Heat storage power $\mathrm{Hs}$ is related to the power of the heat exchanger. This power is lower than the maximum power Hmax of the heat exchanger. That is, the heat storage rate should not exceed the heat transfer rate of the heat exchanger as follows:

$$
\left\{\begin{array}{c}
0 \leq H_{\text {in }, s} \leq H_{i n, \max } \\
0 \leq H_{\text {out }, s} \leq H_{\text {out }, \max }
\end{array}\right.
$$

where Hin,s and Hout,s are the heat entering and exiting the heat storage system, respectively; and Hin,max and Hout,max are the maximum heat entering and exiting the heat exchanger, respectively.

(3) Heating load

As shown in Fig. 9 and in accordance with the law of the conservation of energy, the heat output of the heat storage system Hout,s and the heat from direct electric heating Hd is the sum of the total heating load.

$$
H_{\text {load }}=H_{\text {out }, s}+H_{d}
$$

\section{(4) Heat loss}

In accordance with the law of thermodynamics, energy loss mainly refers to the loss of heat dissipation and heat leakage during practical heat storage. Heat loss is related to the heat storage medium and the surrounding environment. The heat storage medium is assumed to be water, and heat loss is proportional to the ambient temperature. The heat loss coefficient is denoted by kloss, and heat loss is denoted by klossSs. The heat storage system stores heat from time $\mathrm{t}$ to time $\mathrm{t}+1$, and heat is equal to the heat entering the heat storage system minus that exiting the heat storage system and lost. After $\mathrm{T}$ operation period, heat storage restores the original value.

2. Electric heating system model

(1) Electric heating energy conservation

The electric heating load Peh is partially used for electric boiler heat storage Hin,s and for direct heating Hd.

$$
P_{e h}=H_{i n, s}+H_{d}
$$

\section{(2) Power constraints}

The power of the heating system is limited by the power of the grid and the electric boiler. 


$$
\left\{\begin{array}{l}
0 \leq P_{e h, s} \leq P_{e h, \max } \\
0 \leq P_{e h, s} \leq P_{e b, \max }
\end{array}\right.
$$

where Peh,s is the power of the electric power system, Peh,max is the maximum power value of the grid, and Peb,max is the maximum power value of the electric boiler.

\subsection{Analysis of the Heating Effect of Wind Power with Thermal Storage in Dabancheng}

The use of wind power for electric heating with power storage promotes the consumption of wind power. The actual effect includes two aspects: (1) increase in the local electric load and (2) increase in system adjustability. Without heat storage, the electric heating load is equal to the heating load, and the new wind power output curve is the superposition of the original wind power output and the electric heating load curve, as shown in Fig. 10.

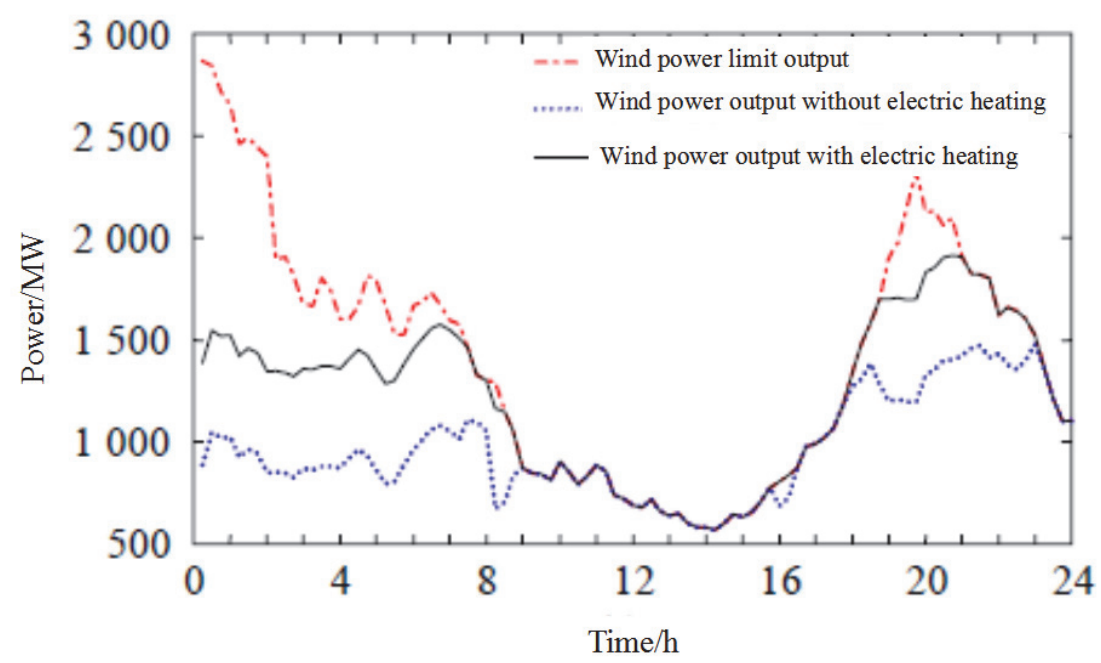

Figure 10. The wind power output curve when wind power heating without heating storage

With heat storage, the electric heating load is equal to the heating load, and the new wind power output curve is the superposition of the original wind power output and the electric heating load curve, as shown in Fig. 11.

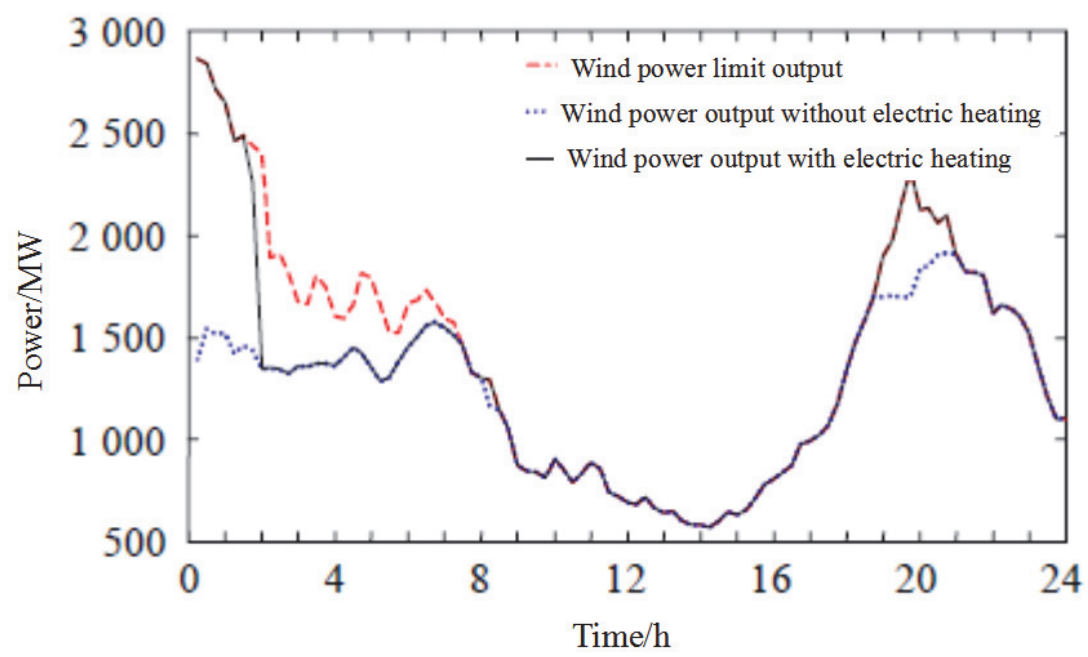

Figure 11. The wind power output curve when wind power heating with heating storage

As shown in Figs. 10 and 11, wind power heating increases electric load, which becomes more evident after adding heat storage. In addition, heat storage has a regulatory function. Wind power curtailment occurs when 
load is low and wind power output is high. Furthermore, the power of the electric heating system is increased, and excess heat can be stored through the storage device. When the electric load and wind power output are low, then the power of the electric heating system is reduced, and the heat of the heat storage device is released to provide heating. Therefore, the heat storage device stores heat during wind power curtailment and releases heat when wind power is abundant. Consequently, the capacity of the wind power heating system is significantly improved, and wind power curtailment is relieved.

\subsection{Economic Benefits of Curtailed Wind Power Heating}

As mentioned in Section 2.4, the heating area of the clean heating station of the Salt Lake community wind power project is $100,000 \mathrm{~m} 2$. The annual amount of the curtailed wind power in the wind power plant is $15,660,000 \mathrm{kWh}$. Compared with traditional coal-fired heating, wind power heating can save 2942 tons of standard coal annually and reduce $\mathrm{CO}_{2}, \mathrm{SO}_{2}, \mathrm{NOx}$, and soot emissions by 5172, 2.9, 22 tons, and 2 tons, respectively.

Electricity cost is 5.269 million yuan per year, and the total annual sales of thermal heating stations is 2.2 million yuan. On this basis, the following two schemes for financial analysis are presented:

Scheme 1: When the static total investment of the heating station is 22.665 million yuan and the financial rate of return of the project is $5 \%$ (before all investment income tax), then the heating station that annually uses the wind power plant subsidies earns a wind power income of 6.093 million yuan (including tax), and the subsidized price is 0.389 yuan $/ \mathrm{kWh}$ (tax included).

Scheme 2: When the static total investment of the heating station is 11.579 million yuan and the financial rate of return of the project is 5\% (before all investment income tax), then the heating station that uses 15.66 million $\mathrm{kWh}$ of the curtailed wind power of the wind power plant per year earns a subsidized income of RMB 4.903 million (equivalent to the subsidized income of 0.313 yuan $/ \mathrm{kWh}$ for the valley).

\section{Multifunctional Wind-Photovoltaic Complementary System with Hydrogen Energy Storage Coupled with the Coal Chemical Industry}

Xinjiang Hami is one of the comprehensive energy bases in China. However, in recent years, the problem of wind and solar power curtailment has become severe, and the coal chemical industry has seriously polluted the environment. Hydrogen storage energy is clean and has wide-ranging application prospects. Accordingly, it has become a research hot spot. The integration of wind power, photovoltaic power, hydrogen storage, and the coal chemical industry is an effective means to solve this problem and reduce pollution (Fan et al., 2017; Ni et al., 2009; Yuan et al., 2015; Zhao, 2sf014). The multifunctional wind-photovoltaic complementary system with hydrogen energy storage coupled with the coal chemical industry is therefore established. The system includes a mixed wind and solar energy system, a power distribution system, a hydrogen storage system, a gas distribution system, a coal chemical system, a waste heat utilization system, and a methanol/dimethyl ether/O2/H2 mixed power generation system. The system is shown in Fig. 12 (Fan et al., 2017). 


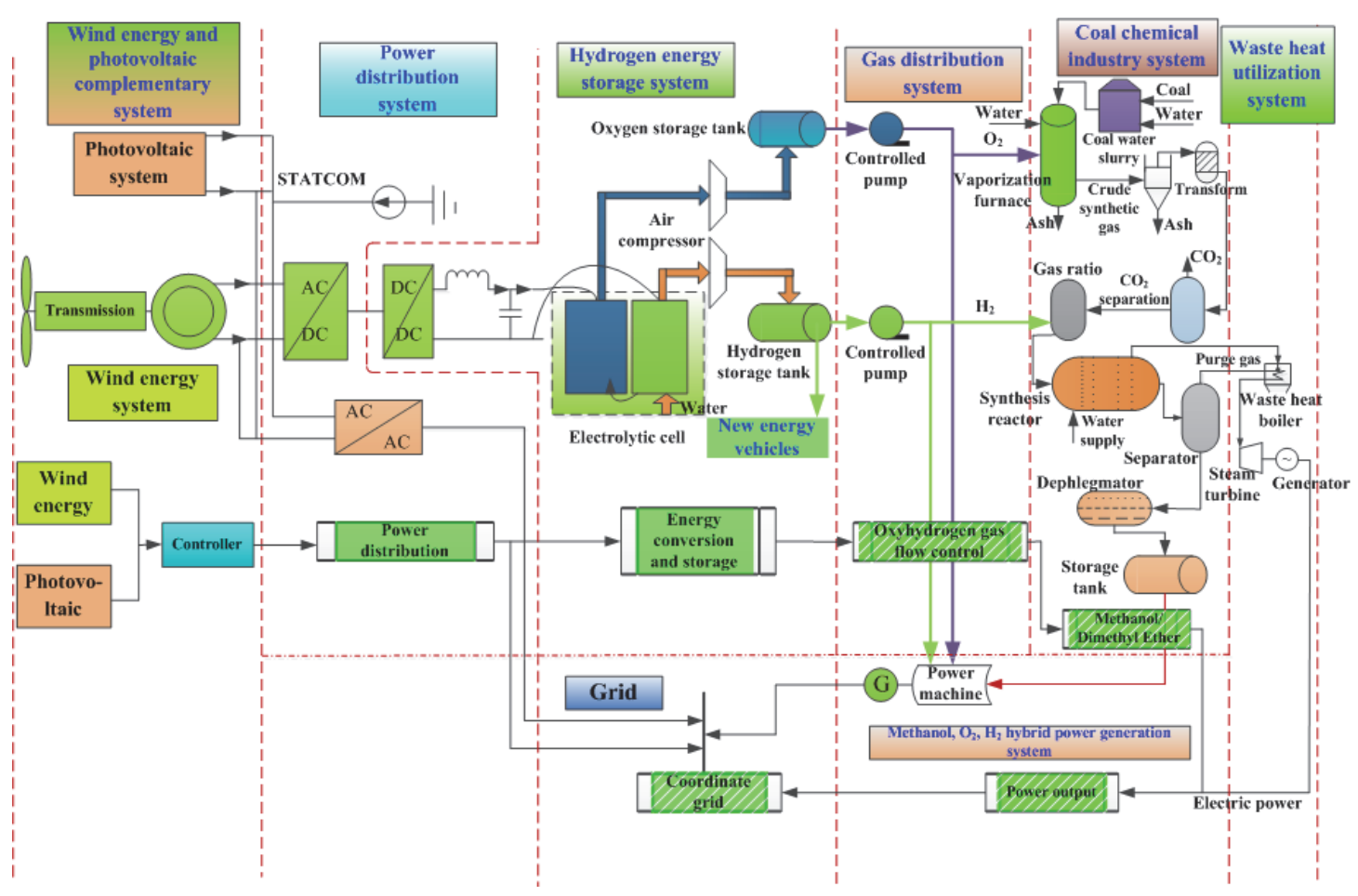

Figure 12. Hybrid power generation and energy storage system of the wind photovoltaic complementary-hydrogen energy storage coupling with coal chemical industry

After passing through the inverter, power is partially used for connecting to the grid and for generating AC power. Power is used to electrolyze water to generate $\mathrm{O} 2$ and $\mathrm{H} 2$. $\mathrm{O} 2$, as a gasification medium, is delivered to the gasifier. $\mathrm{H} 2$ is partially used as the renewable energy vehicle fuel and methanol feed gas that mixes with the carbon-rich syngas produced by the gasifier. Then, $\mathrm{H} 2 / \mathrm{CO}$ mixture is adjusted to the appropriate proportion for methanol/dimethyl ether production. Qualified methanol and dimethyl ether are produced after the feed gas passes through the synthesis reactor, separator, and redistillation unit. The methanol and dimethyl ether are partially used as chemical raw materials and fuel to constitute a hybrid power generation system that mixes $\mathrm{O} 2$ and $\mathrm{H} 2$. In addition, the purge gas in the separator of the coal chemical system can be reused as a heat source to heat the air. The hot air acts as a driving force to promote low steam turbine power generation. The waste steam can be used for heating to keep the system components warm.

The use of wind power and the photovoltaic electrolysis of water to produce $\mathrm{O} 2$ and $\mathrm{H} 2$ do not only eliminate the requirement for an expensive and high energy-consuming air separation device, but also allows for the adjustment of the mixing ratio of carbon-rich syngas in the new system, unlike the traditional coal-based methanol production system. Furthermore, the minor transformation process based on the type of coal can substantially reduce the conversion of carbon-rich syngas. Consequently, the emission of $\mathrm{CO}_{2}$ is effectively reduced. In Fig. 12, $\mathrm{O} 2$ and $\mathrm{H} 2$ gas tanks are used to balance the unstable wind power and photovoltaic power. Coal chemical production is relatively stable.

The integration of wind power, photovoltaic power, and hydrogen energy storage coupled with a coal-based methanol production into a multi-energy system presents a win-win energy solution with the following advantages:

1) Large-scale wind power and photovoltaic power are used completely and reasonably. Through the integration of methanol, wind power, and photovoltaic power, the difficulty in connecting wind power and photovoltaic systems to the grid, among other issues, can be effectively solved.

2) $\mathrm{CO}_{2}$ emissions can be reduced to approximately one-fourth of the $\mathrm{CO}_{2}$ emissions from traditional coal-based energy and chemical methanol production systems. Methanol and dimethyl ether are produced using a "green" approach.

3) The unit utilization efficiency of coal is efficiently improved, and methanol production is increased by over 
two-thirds per unit of coal consumption.

4) The water consumption of the coal chemical industry is decreased. The water consumption of the methanol production unit is reduced by one-third. This reduction is significant to Hami, which abounds in coal, wind, and light resources, but faces water shortage.

5) $\mathrm{H} 2 / \mathrm{CO}$ is utilized in various stages. Most of the carbon content in coal and all the hydrogen and oxygen contents of the electrocuting water enter the methanol product. Consequently, interference and influence on the ecological environment are minimized.

The implementation plan for the wind and solar complementary system for hydrogen production, storage, and application is presented in Fig. 13 (Fan et al., 2017).

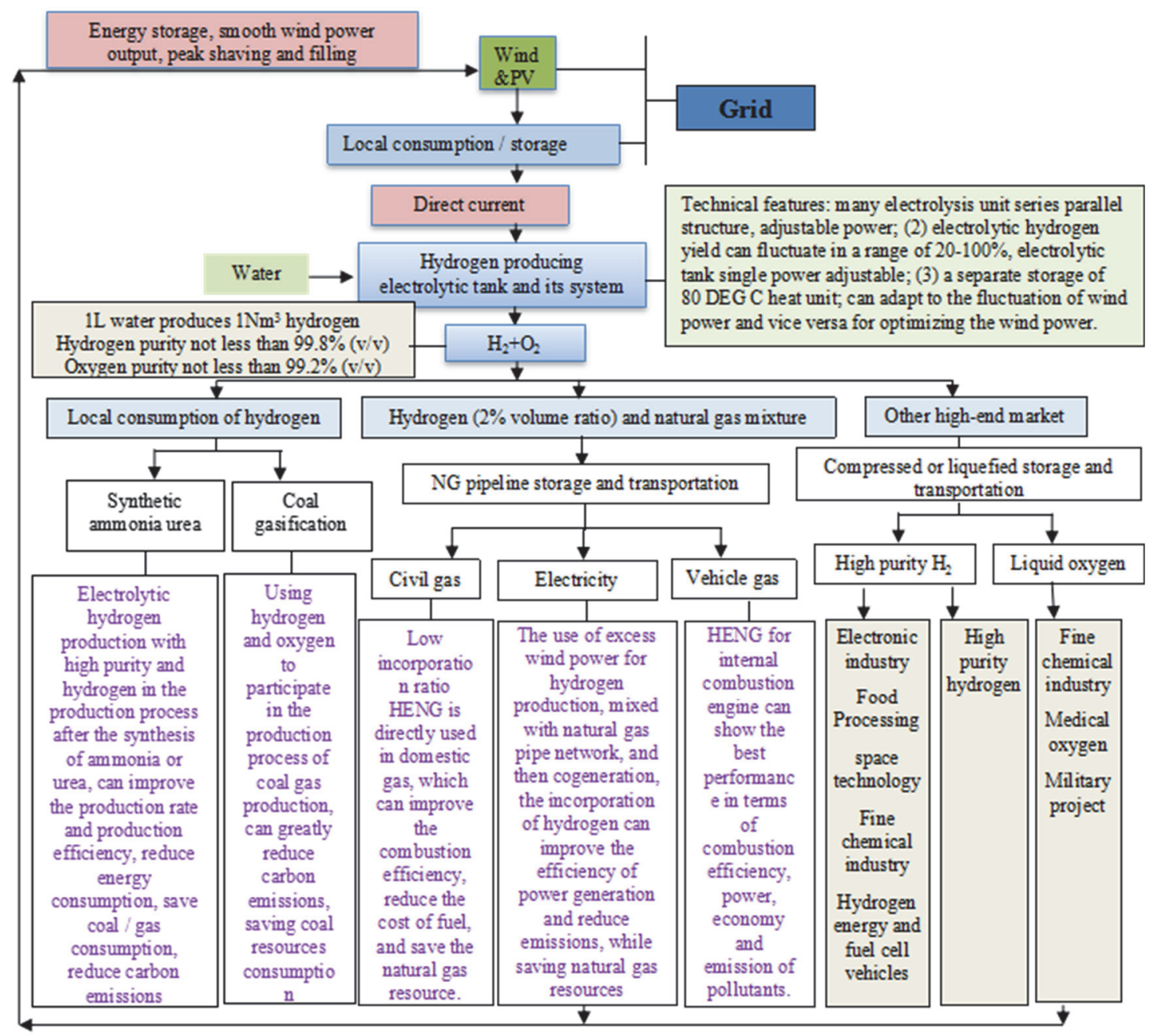

Figure 13. The implementation plan of wind and solar complemented for hydrogen production, storage, application

\section{Conclusions}

In this study, wind power load is increased to improve the consumption of wind power. The use of curtailed wind power in Dabancheng Wind Farm for clean heating is studied, and the results show that wind power heating is feasible in Dabancheng Wind Farm. In particular, the wind power heating system with heating storage can reduce wind power curtailment, increase the consumption market, and adjust load. Non-grid-connected distributed wind power is applied to the high energy-consuming industries. This solution can also reduce curtailed wind power, increase the consumption market, and reduce pollution. A multifunctional windphotovoltaic complementary system with hydrogen energy storage coupled with the traditional high energy-consuming coal chemical industry in Hami is constructed, and an implementation plan is designed to 
combine wind and solar energy for hydrogen production, storage, and application. The system and the implementation plan should be studied further and will be the focus of our future research.

China currently advocates low-carbon green development. Xinjiang is rich in renewable energy, and the region has considerable development space. In the near future, Xinjiang is expected to develop and use renewable energy extensively. The renewable energy industry will hold a dominant position in its energy structure. However, the joint efforts of all sectors of society are required. China has proposed the global energy Internet strategy (Fan et al., 2017) and vigorously promoted the development and utilization of clean energy. Xinjiang is a core area in the Silk Road Economic Belt. Through this global energy Internet strategy and large-scale Xinjiang power delivery, Xinjiang can actively participate in the optimal allocation of energy in China and the neighboring regions of Xinjiang. Ultimately, the sustainable development of the wind power industry in Xinjiang is promoted.

\section{Acknowledgments}

This study forms part of a research project supported by the Natural Science Foundation of China (Nos.51666017, 51667020, 51567022), the Hebei science and technology plan project (No.15214370D), the Natural Science Foundation of Xinjiang Uygur Autonomous Region (Nos.2016D01C062, 2017D01A026), the Xinjiang Uygur Autonomous Region Outstanding Youth Scientific and Technological Personnel Training Project(No.QN2016JQ0288), and the Xinjiang University Doctoral Foundation Project(No.2017XJUD068). The authors would like to express their gratitude for the support of these funding authorities.

\section{References}

Alahäivälä, A., Ekström, J., \& Jokisalo, J., et al. (2017). A framework for the assessment of electric heating load flexibility contribution to mitigate severe wind power ramp effects. Electric Power Systems Research, 142, 268-278.

Biviano, I., Lezoche, E., \& Paganini, A. M., et al. (2015). Sa1344 Anal Function After Transanal Endoscopic Microsurgery (TEM) and Radiotherapy for Distal Rectal Cancer. Gastroenterology, 148(4), S-297-S-298.

Chalise, S., Atia, H. R., \& Poudel, B., et al. (2015). Impact of Active Power Curtailment of Wind Turbines Connected to Residential Feeders for Overvoltage Prevention. IEEE Transactions on Sustainable Energy, $7(2), 1-9$.

Chen, Y., Li. Z., \& Li, W., et al. (2016). Water and ecological security: dealing with hydroclimatic challenges at the heart of China's Silk Road. Environmental Earth Sciences, 75(10), 881.

Fan, X. C., Wang, W. Q., \& Shi, R. J. (2015). Analysis and countermeasures of wind power curtailment in China. Renewable \& Sustainable Energy Reviews, 52, 1429-1436.

Fan, X. C., Wang, W. Q., \& Shi, R. J. (2017). Hybrid pluripotent coupling system with wind and photovoltaic-hydrogen energy storage and the coal chemical industry in Hami, Xinjiang. Renewable and Sustainable Energy Reviews, 72, 950-960.

Fei, X. U., Yong, M., \& Lei, C., et al. (2014). Combined Electricity-Heat Operation System Containing Large Capacity Thermal Energy Storage. Proceedings of the CSEE, 34(29), 5063-5072.

Kane, L., \& Ault, G. W. (2015). Evaluation of Wind Power Curtailment in Active Network Management Schemes. Power Systems IEEE Transactions on, 30(2), 672-679.

Lei, C., Fei, X. U., \& Xiao, W., et al. (2015). Implementation and Effect of Thermal Storage in Improving Wind Power Accommodation. Proceedings of the CSEE, 35(17), 4283-4290.

Li, P., Qian, H., \& Howard, K. W. F., et al. (2015). Building a new and sustainable "Silk Road economic belt". Environmental Earth Sciences, 74(10), 7267-7270.

Li, Q. Y., Feng, L., \& Xu, Y. H. et al. (2012). Accommodation Mode of Wind Power Based on Water Source Heat Pump Technology. Automation of Electric Power Systems, 36(17), 25-27.

Liu, D., Zhang, G., \& Huang, B., et al. (2016). Optimum Electric Boiler Capacity Configuration in a Regional Power Grid for a Wind Power Accommodation Scenario. Energies, 9(3), 144.

Long, H., Xu, R. L., \& He, G. J., et al. (2013). Analysis of peak-load regulation capability based on combined dispatch of wind power and thermal power. Electric Power Automation Equipment, 33(4), 30-34+54.

Luo, G. L., Li, Y. L., \& Tang, W. J. (2016). Wind curtailment of China's wind power operation: Evolution, causes and solutions. Renewable \& Sustainable Energy Reviews, 53, 1190-1201. 
Ma, Z., Xue, B., \& Geng, Y., et al. (2013). Co-benefits analysis on climate change and environmental effects of wind-power: A case study from Xinjiang, China. Renewable Energy, 57(3), 35-42.

Ni, W. D., Gao, J., \& Chen, Z., et al. (2009). How to make the production of methanol/DME "GREENER"-Integration of wind power with modern coal chemical industry. Frontiers in Energy, 3(1), 94-98.

Pei, W., Chen, Y., \& Sheng, K. (2015). Temporal-spatial analysis and improvement measures of Chinese power system for wind power curtailment problem[J]. Renewable \& Sustainable Energy Reviews, 49, 148-168.

Quan, L., Chen, T., \& Wang, H., et al. (2014). Combined heat and power dispatch model for power system with heat accumulator. Electric Power Automation Equipment, 34(5), 79-85.

Quan, L., Hao, J., \& Chen, T., et al. (2014). Wind Power Accommodation by Combined Heat and Power Plant with Electric Boiler and Its National Economic Evaluation. Automation of Electric Power Systems, 38(1), 6-12.

Shi, R. J., Fan, X. C., \& He, Y. (2017). Comprehensive evaluation index system for wind power utilization levels in wind farms in China. Renewable \& Sustainable Energy Reviews, 69, 461-471.

Wang, C., Zhang, H., Fan, W., \& Fan, X. (2016). A new wind power prediction method based on chaotic theory and Bernstein Neural Network. Energy, 117, 259-271.

Wu, C. B., Huang, G. H., \& Li, W., et al. (2016). An inexact fixed-mix fuzzy-stochastic programming model for heat supply management in wind power heating system under uncertainty. Journal of Cleaner Production, $112,1717-1728$.

Xue, B., Ma, Z., \& Geng, Y., et al. (2015). A life cycle co-benefits assessment of wind power in China. Renewable \& Sustainable Energy Reviews, 41, 338-346.

Yang, J., \& Chen, B. (2016). Energy-water nexus of wind power generation systems. Applied Energy, 169, 1-13.

Yuan, T., Hu, K. L., \& Guan, Y., et al. (2015). Modeling on Hydrogen Producing Progress in EMR Based Wind Power-hydrogen Energy Storage and Coal Chemical Pluripotent Coupling System. High Voltage Engineering, 41(7), 2156-2164.

Yuan, X., Cheng, S., \& Wen, J. (2013). Prospects Analysis of Energy Storage Application in Grid Integration of Large-scale Wind Power. Automation of Electric Power Systems, 37(1), 14-18.

Zhao, X. Y. (2014). Potential Analysis of Wind-Solar Hybrid Electricity Generation and Research on System Optimization Design. Zhengzhou:Agricultural University Of He'nan, 2014.

\section{Web References}

http://www.cec.org.cn/yaowenkuaidi/2013-01-18/96345.html

http://www.gov.cn/_zwgk/2013-09/12/content_2486773.htm

http://www.nea.gov.cn/2015-04/17/c_134160176.htm

http://www.nea.gov.cn/2016-02/02/c_135066586.htm

http://zfxxgk.nea.gov.cn/auto87/201303/t20130322_1599.htm?keywords=

http://zfxxgk.nea.gov.cn/auto92/201602/t20160216_2202.htm

\section{Copyrights}

Copyright for this article is retained by the author(s), with first publication rights granted to the journal.

This is an open-access article distributed under the terms and conditions of the Creative Commons Attribution license (http://creativecommons.org/licenses/by/4.0/). 